\title{
Relapsed testicular lymphoma presenting with cranial nerve neurolymphomatosis
}

\section{Figure Brain MRI}
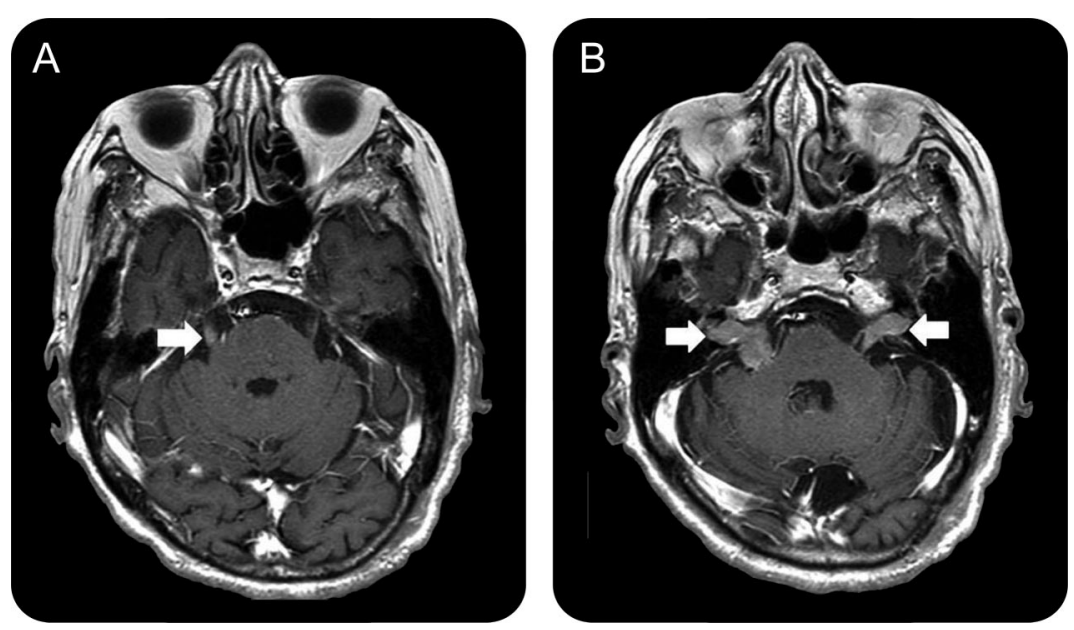

Brain MRI revealed abnormal thickening of right trigeminal nerve ( $\mathrm{A}$, arrow) and bilateral acousticovestibular nerves $(B$, arrows), which extended into bilateral internal acoustic meati.

Rapidly progressive hearing loss and dizziness developed in an 82-year-old man with testicular diffuse large B-cell lymphoma, treated 3 years previously. Examination revealed bilateral hearing loss, mild right facial palsy, and wide-base gait. Brain MRI revealed thickening of the right V and bilateral VII and VIII nerves (figure), without brain or meningeal involvement. The CSF showed no malignant cells. The absence of brain parenchymal disease suggested cranial nerve neurolymphomatosis, infiltration by neurotropic neoplastic cells, a rare manifestation of hematologic malignancy. ${ }^{1}$ Testicular lymphoma may involve the CNS, but rarely with cranial nerve neurolymphomatosis. ${ }^{2}$

\section{Man-Hsin Hung, MD, Jyh-Pyng Gau, MD, Taipei, Taiwan}

Disclosure: Dr. Hung reports no disclosures. Dr. Gau receives research support from Taipei Veterans General Hospital and Taiwan Clinical Oncology Research Foundation.

Address correspondence and reprint requests to Dr. Jyh-Pyng Gau, Division of Hematology and Oncology, Department of Medicine, Taipei Veterans General Hospital and National Yang-Ming University School of Medicine, No 201, Section 2, Shih-Pai Road, Taipei, Taiwan; jpgau@vghtpe.gov.tw

1. Grisariu S, Avni B, Batchelor TT, et al. Neurolymphomatosis: an International Primary CNS Lymphoma Collaborative Group report. Blood 2010;115:5005-5011.

2. Vitolo U, Ferreri A, Zucca E. Primary testicular lymphoma. Crit Rev Oncol Hematol 2008;65:183-189. 


\section{Neurology}

\section{Relapsed testicular lymphoma presenting with cranial nerve neurolymphomatosis}

Man-Hsin Hung and Jyh-Pyng Gau

Neurology 2011;76;1441

DOI 10.1212/WNL.0b013e318216711a

\section{This information is current as of April 18, 2011}

\section{Updated Information \&} Services

\section{References}

\section{Subspecialty Collections}

Permissions \& Licensing

Reprints including high resolution figures, can be found at: http://n.neurology.org/content/76/16/1441.full

This article cites 2 articles, 1 of which you can access for free at: http://n.neurology.org/content/76/16/1441.full\#ref-list-1

This article, along with others on similar topics, appears in the following collection(s):

All Clinical Neurology

http://n.neurology.org/cgi/collection/all_clinical_neurology

Metastatic tumor

http://n.neurology.org/cgi/collection/metastatic_tumor

MRI

http://n.neurology.org/cgi/collection/mri

Nerve tumor

http://n.neurology.org/cgi/collection/nerve_tumor

Vertigo

http://n.neurology.org/cgi/collection/vertigo

Information about reproducing this article in parts (figures,tables) or in its entirety can be found online at:

http://www.neurology.org/about/about_the_journal\#permissions

Information about ordering reprints can be found online: http://n.neurology.org/subscribers/advertise

Neurology ${ }^{\circledR}$ is the official journal of the American Academy of Neurology. Published continuously since 1951, it is now a weekly with 48 issues per year. Copyright Copyright @ 2011 by AAN Enterprises, Inc.. All rights reserved. Print ISSN: 0028-3878. Online ISSN: 1526-632X.

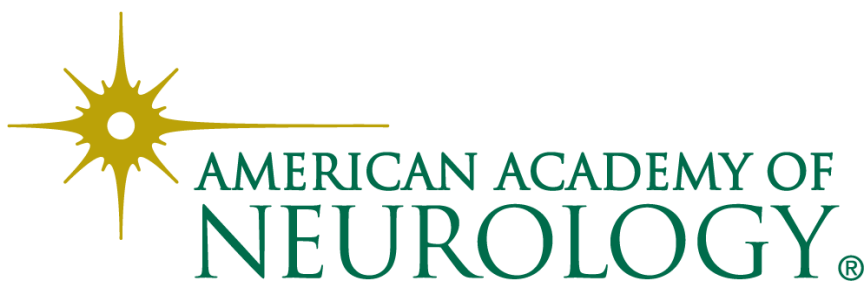

